\title{
Unique simultaneous dual mechanism based bilateral femoral head fracture secondary to posterior dislocation of hip: A rare case report
}

\author{
Daksh Gadi $^{{ }^{*}}$, Ravinder Singh ${ }^{2}$, Vikas Anand ${ }^{3}$, Subodh Pathak ${ }^{4}$ \\ ${ }^{I}$ Fellow in Arthroplasty, Fortis Hospital, Ludhiana and Senior resident, Department of Orthopaedics, \\ MM Institute of Medical Sciences and Research, Mullana, Ambala, Haryana. India \\ ${ }^{2}$ Professor, MM Institute of Medical Sciences and Research, Mullana \\ ${ }^{3}$ Assistant professor, MM Institute of Medical Sciences and Research, Mullana \\ ${ }^{4}$ Resident, Pramukhswami Medical college and Shree Krishna hospital, Karamsad, Anand \\ *Corresponding author E-mail:Dr_daksh@yahoo.com
}

\begin{abstract}
Hip joint being surrounded by strong ligaments and muscles is considered a stable joint and dislocations are exceptionally rare. Majority of the dislocations are unilateral and are secondary to a high velocity traumatic injury making a bilateral dislocation a rare entity. Due to high velocity injury, femur head and acetabular wall fractures have been associated to dislocations and each of the associated injuries occurs with a different mechanism of injury. In view of its rarity we hereby have reported a unique mechanism based case of bilateral posterior dislocation of hip with bilateral femoral head fracture.
\end{abstract}

Keywords: Femur Head Fracture; Hip Dislocation.

\section{Introduction}

Hip joint is a ball and socket joint with strong ligamentous attachments, labrum and surrounding musculature is considered most stable joint. A dislocation thus requires a high energy trauma to displace the femur head outside the acetabular cavity (Louis Traore et al. 2015). Majority of hip dislocations are of posterior type (Dreinhofer KE et al. 1994) and unilateral with overall incidence of 5\% (Letenneur J et al. 1978). Dislocation type depends upon the position of the hip, the vectoral force applied and the individual anatomy (Upadhyay SS et al. 1985). Posterior dislocation usually occurs due to a deceleration car accident with the dashboard striking the knee resulting in an axial force in a flexed hip and knee. Such dislocations may or may not be associated with fractures depending upon the attitude of patient during the injury. Literature suggests that in a flexion adduction attitude of hip, chances of fractures are less as compared to less adduction (Letournel E et al 1957). This is only true for the acetabular wall fractures but no study clearly suggests the mechanism of fractures of the head of femur. Pipkins (Pipkins G 1993) and Brumback (Brumback RJ et al. 1987) have classified the fractures of femoral head associated with dislocations based upon the fragment.

Femoral head fractures mainly are due to impact or may be due to shearing force in which the pull of ligamentum teres keep the fracture fragment in the acetabular cavity. According to best of our knowledge, few cases have been reported of femoral head fracture in which the fracture is below the attachment of ligamentum teres associated to a dislocation. Hereby we have reported a bilateral femoral head fracture posterior dislocation of hip suggesting a bilateral shear force injury.

\section{Case vignette}

A $26 \mathrm{Yr}$ old gentleman presented to the casualty with a history of road traffic accident. The patient was travelling in a car sitting beside the driver seat when there was a head on collision of the car with a truck. The patient was sitting unrestrained in the car during the accident and had sustained injury to his forehead and complained of severe pain in both the hips and was not able to stand. Patient's vitals were with in normal limits and GCS was 15/15.

On clinical examination, patient hip was in attitude of flexion, adduction and internal rotation at both hip joints. Hip range of movement was severely tender and restricted. Detailed neurological examination revealed no motor or sensory weakness.

An emergency radiograph of pelvis was taken which suggested bilateral fracture dislocation of the hip (fig 1). Femoral head fracture and posterior wall fracture was suspected so a CT scan was done to visualize the fragments and their orientation (fig 2). A femoral head fracture caudal to the ligamentum teres on the left side was noted suggesting a shear force injury (fig 3). An avulsion fracture of femur head (fig 4) associated with a posterior wall fracture of acetabulum (fig 5) was noted on the right side. An intraarticular fragment on the right side with a posteriorly dislocated head on the right side was also visualized (fig 5). Based upon the severity of fracture patient was advised emergency open reduction of dislocation and fracture fixation using Herbert screws. Patient requested to go to another hospital for management after the first aid and stabilisation. 


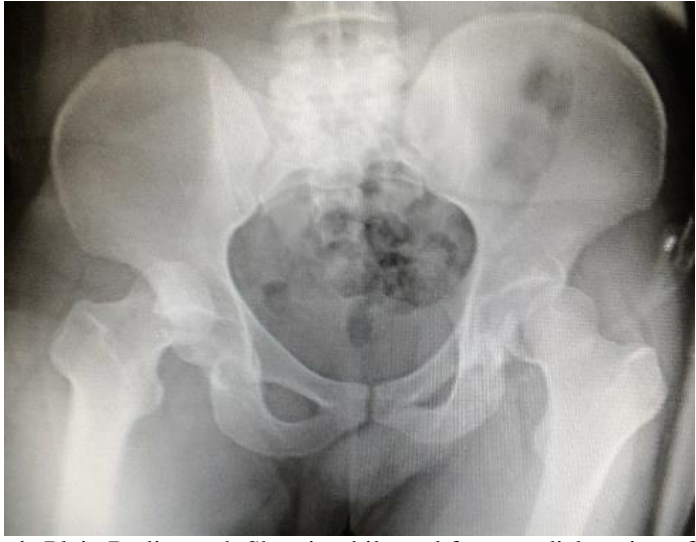

Fig. 1: Plain Radiograph Showing bilateral fracture dislocation of hip

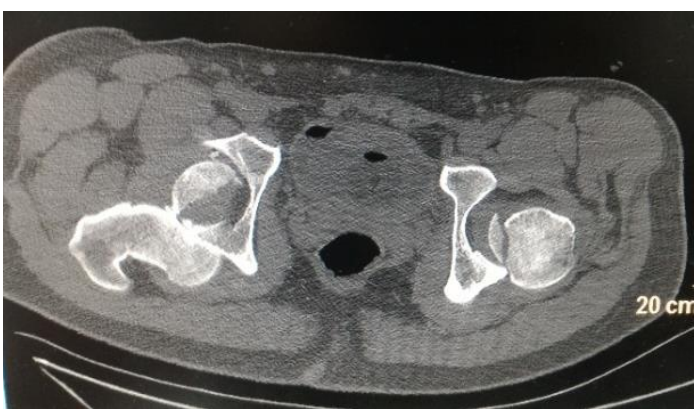

Fig 2: Axial CT Showing Dual Mechanism Femoral Head Fracture with b/l Dislocation of Hip

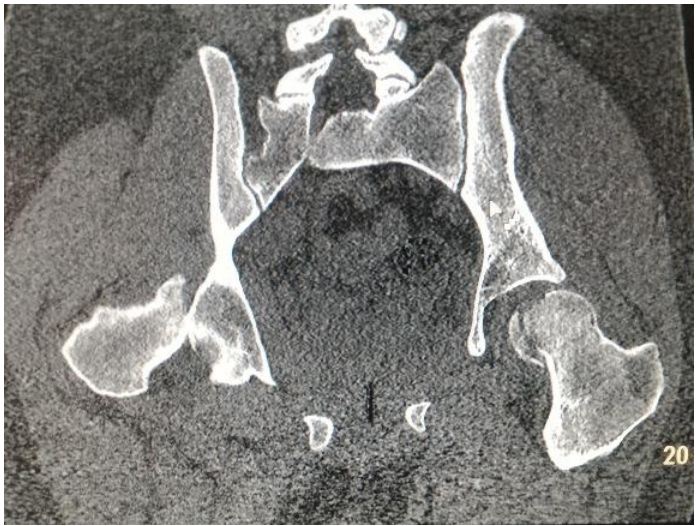

Fig. 3: Vertical Shear Left Femoral Head Fracture

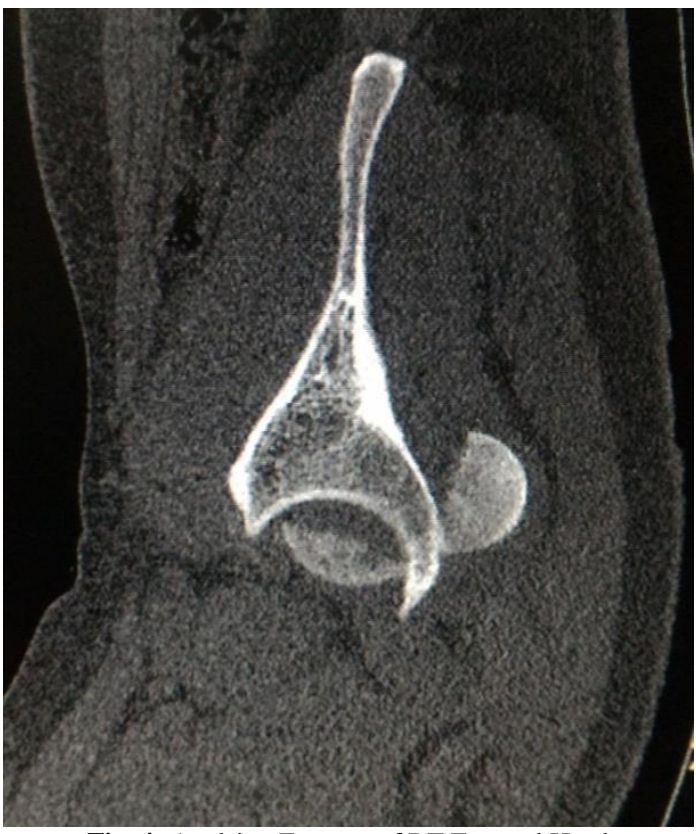

Fig. 4: Avulsion Fracture of RT Femoral Head

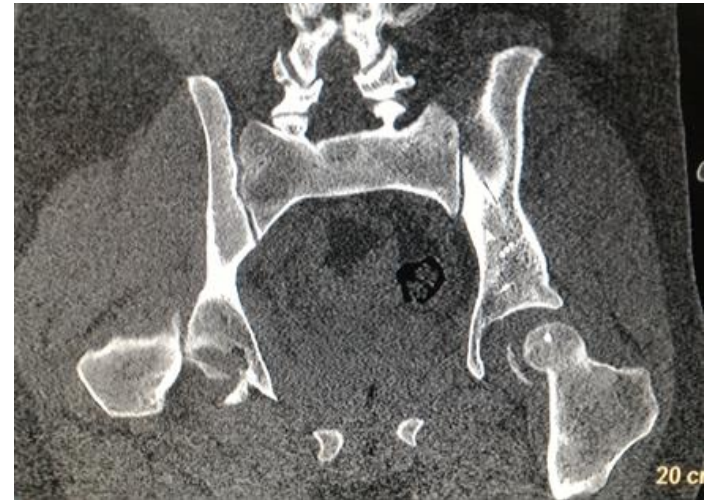

Fig. 5: Posterior Acetabular Wall Fracture with Intra-Articular Fragment

\section{Discussion}

Bilateral posterior dislocation of hip was first described by Marquardt in 1937 (I.Elouakili et al. 2011). In view of the stability of hip joint, bilateral dislocation is a rare entity (Kozin $\mathrm{SH}$ et al. 1994). It is usually associated with a high energy trauma usually a road traffic accident. In our case due to the presence of bilateral dislocation with both the head of femur fractures of different pattern suggest a unique mechanism of injury. There is a dual force injury wherein a combination of shear force and axial vectoral force leading to an avulsion fracture by the pull of ligamentum teres is seen. To the best of our knowledge presence of both types of fracture with a bilateral dislocation simultaneously is a very rare entity and needs to be reported.

In our case due to a head on collision and patient attitude of flexed hip and knee unrestrained lead to a typical dashboard injury with the patient falling forward and hitting the dashboard of the vehicle. This caused an avulsion fracture of the right femur head due to pull of the ligamentumteres keeping the fracture fragment well inside the acetabular cavity. Whereas on the left side the fracture had occurred due to a shear force with the fracture fragment below the fovea centralis. Thus creating a unique and a rare mechanism for the fracture dislocation.

The treatment protocol in such patient is open reduction and internal fracture fixation within 6 hours of injury to decrease the future complications of avascular necrosis of head of femur and early onset arthritis.

Thus due to the poor prognosis and high complication rates, a high index of suspicion should be kept in all high energy trauma cases where posterior dislocation may be associated with such fractures.

\section{Conclusion}

Bilateral hip dislocations and such unusual associated fractures although being a rare entity, it is essential to diagnose such fractures early to start prompt treatment. All orthopaedic surgeons should keep a high index of suspicion to evaluate such rare cases with CT scan for localising the fracture fragments. This case report will help in understanding the dual mechanism of femur head fractures in bilateral dislocation of hip.

\section{References}

[1] Louis Traore, AbdoukadriMoussa, LoubetUnyendje, Mustapha Mahfoud, Berradasaleh Mohamed, Moradh el Yaacoubi. Bilateral traumatic dislocation of hip associated with fractures of two obturator rings (a case report). International Journal of Recent Scientific Research. 2015 6(2): 2794-2796

[2] Dreinhofer KE, Schwarzkopf SR, Haas NP, et al. Isolated traumatic dislocation of the hip. J Bone Joint Surg Br 1994; 76: 6-12

[3] Letenneur J, Fleuriel M, Sanguy D, Incarcérationosseuse intraarticulaire après reduction de luxation de hanche. ProblèmediagnostiqueETthérapeutique. J chir 1978; 115: 97-100. 
[4] Upadhyay SS, Moulton A, Burwell RG. Biological factors predisposing to traumatic posterior dislocation of the hip. J Bone Joint Surg $\mathrm{Br}$ $1985 ; 67: 232-236$

[5] Letournel E, Judet R. Fractures of the Acetabulum, 2nd ed. New York: Springer-Verlag; 1993http://dx.doi.org/10.1007/978-3-642-75435-7.

[6] Pipkin G. Treatment of grade IV fracture dislocation of the hip. J Bone Joint Surg Am 1957; 39:1027-1042.

[7] Brumback RJ, Kenzora JE, Levitt LE et al. Fractures of the femoral head. Hip 1987;181-206.

[8] I.Elouakili, M.Chabouni, A.Najib et al. Luxation traumatiquebilatérale

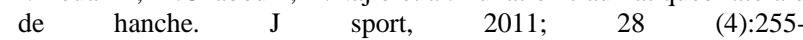
256http://dx.doi.org/10.1016/j.jts.2011.10.006.

[9] Kozin SH, Kolessar DJ, Guanche CA, Marmar EC. Bilateral femora head fracture with posterior hip dislocation. Orthop Rev. 1994:20-24. 